\title{
ATOMIC FORCE MICROSCOPY STUDIES OF THE SURFACE SCALE FORMED DURING OXIDATION OF INCOLOY MA956
}

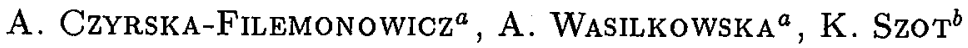 \\ AND W.J. QUADAKKERS ${ }^{c}$
}
${ }^{a}$ Faculty of Metallurgy and Materials Science, University of Mining and Metallurgy Al. Mickiewicza 30, 30-059 Kraków, Poland
${ }^{b}$ Faculty of Physics, Silesian University, Uniwersytecka 4, 40-007 Katowice, Poland 'Institute for Materials in Energy Systems, Research Centre Jülich 52428 Jülich, Germany

The formation of thin oxide films on $\{111\}$ and $\{110\}$ single crystal specimens of $\mathrm{Fe} 20 \mathrm{Cr} 5 \mathrm{Al}$ based oxide dispersion strengthened alloy during the early stages of oxidation up to $1000^{\circ} \mathrm{C}$ was investigated by atomic force microscopy. The atomic force microscopy results revealed the crystalline character of a corrosion layer. The alumina scale morphology (height and grain size of crystallites) was only slightly dependent on the crystallographic texture of the underlying bulk material. The results show that atomic force microscopy has the potential to study surface structure of oxide layers in the initial stages of an oxidation process.

PACS numbers: $68.55 .-\mathrm{a}$

\section{Introduction}

INCOLOY MA956 is an oxide dispersion strengthened (ODS) alloy, which exhibits very good oxidation resistance up to around $1100^{\circ} \mathrm{C}$, mainly due to a protective alumina surface scale, which is characterised by slow growth rates and excellent adherence [1].

The mechanisms and processes of scale formation occurring in the early stages of oxidation have not been intensively investigated, although in many cases it has been shown that transient oxidation features can significantly affect long time scale properties. A new technique for such studies is atomic force microscopy (AFM), which allows detailed topographic information of the real surface to be obtained. In the study presented, the morphological features of a nanometer thick oxide film formed after short time oxidation of well defined single crystals were investigated by AFM. 


\section{Experimental details}

INCOLOY MA956 was supplied as hot extruded and recrystallized bar $\left(1330^{\circ} \mathrm{C} / 1 \mathrm{~h}\right)$ of $20 \mathrm{~mm}$ diameter. Chemical composition of a bar was as follows: $\mathrm{Fe}-19.9 \mathrm{Cr}-4.6 \mathrm{Al}-0.4 \mathrm{Ti}-0.5 \mathrm{Y}_{2} \mathrm{O}_{3}$ (in wt\%). The macrostructure of the as received bar exhibits columnar grains with particularly coarse grain size (up to few millimetres) and crystallographic texture very close to the (111) direction, parallel to the extrusion direction of the bar [2]. The microstructure of MA956 consists of fine dispersoids $\mathrm{Y}_{2} \mathrm{O}_{3} \cdot \mathrm{Al}_{2} \mathrm{O}_{3}$ with a mean diameter of $22 \mathrm{~nm}$ and some larger particles of $\mathrm{Al}_{2} \mathrm{O}_{3}$ and $\mathrm{Ti}(\mathrm{C}, \mathrm{N})$ in a ferritic matrix [3].

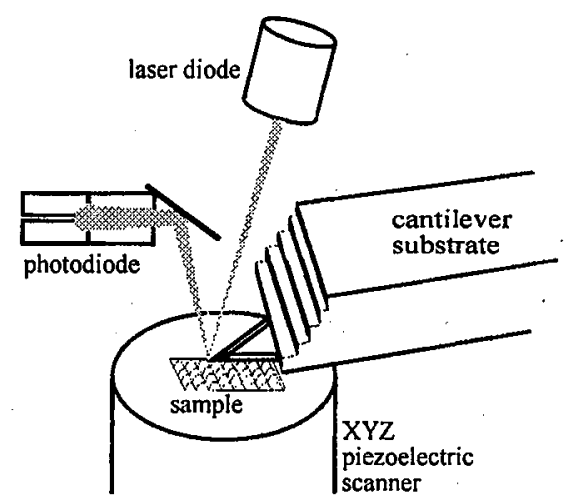

Fig. 1. Schematic diagram of the AFM (NanoScope microscope) technique.

The particularly coarse grain size of the MA956 bar allowed single crystal specimens of about $5 \times 5 \times 2 \mathrm{~mm}^{3}$ to be spark machined. The crystallographic orientation of the specimens was measured by the X-ray Laue method. Two specimen sets, with orientations $\langle 110\rangle$ and $\langle 111\rangle$, were prepared for the oxidation studies. The samples were mounted in a special goniometer holder, which enables to keep an orientation $\pm 2^{\circ}$ during the polishing. The mirror-like prepared surfaces (roughness about $1.2 \mathrm{~nm}$ ) were subjected to oxidation at 800 and $1000^{\circ} \mathrm{C}$ for 0.5 and $1.5 \mathrm{~h}$. AFM investigations have been performed $e x$ situ using a commercial NanoScope (Fig. 1), operated in tapping mode. The topographic data from the surface examined are obtained due to the deflection of a silicon-based tip, which scans the specimen surface at a close distance. The cantilever bending is monitored by an optical system: the beam from a laser diode is focused onto the back of the cantilever and then reflects onto a segmented photodiode. The amplified differential signal between the upper and lower photodiodes provides a sensitive measure of the deflection.

\section{Results and discussion}

The formation of a thin oxide film on MA956 was studied as a function of the substrate crystallographic orientation, as well as temperature and oxidation time. Even in the early stages of oxidation, AFM images revealed a crystalline character of the scale (Figs. 2 and 3). The morphology of the growing scale seemed to be 

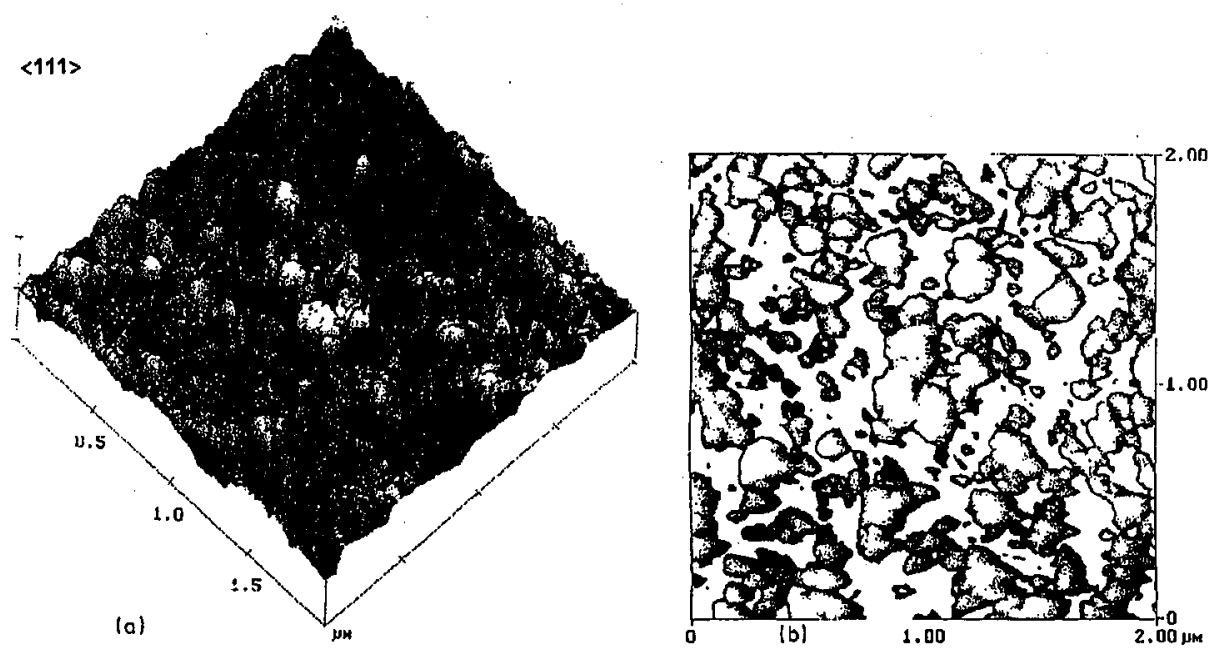

Fig. 2. (a) AFM images of the oxide film morphology and (b) plane section of crystallites formed on $\langle 111\rangle$ specimens during oxidation at $800^{\circ} \mathrm{C}$ for $1.5 \mathrm{~h}$.
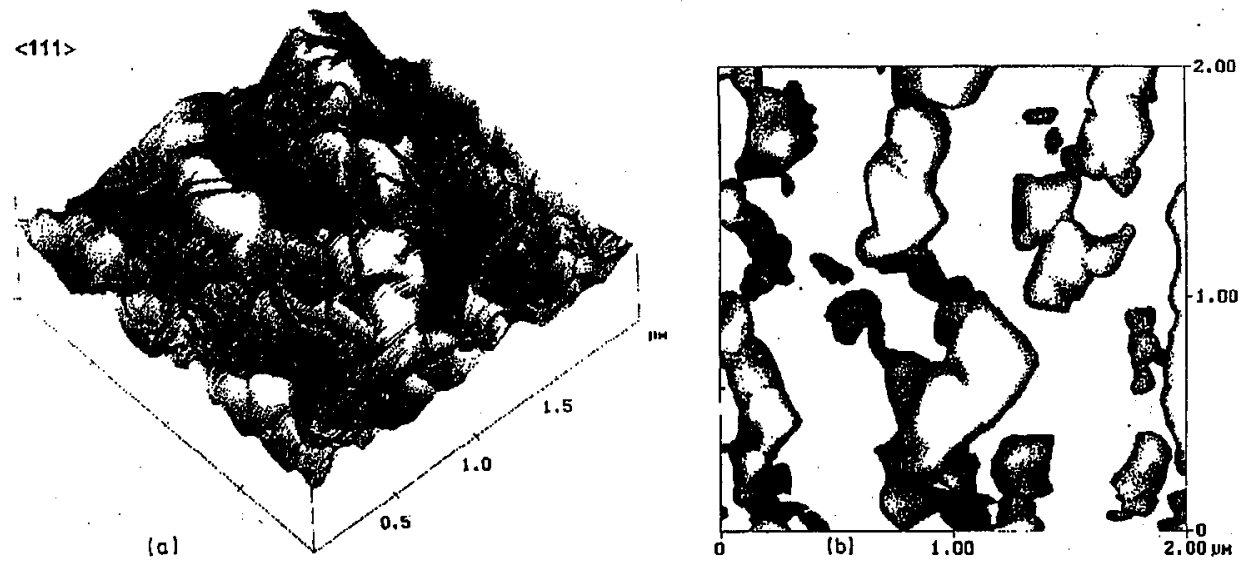

Fig. 3. (a) AFM images of the oxide film morphology and (b) plane section of crystallites formed on $\langle 111\rangle$ specimens during oxidation at $1000^{\circ} \mathrm{C}$ for $1.5 \mathrm{~h}$.

related to the crystallographic texture of the underlying bulk material, which can influence the absorption processes.

The results of quantitative AFM evaluations are presented in Table. The oxide crystallites formed on the surface of the $\langle 110\rangle$ specimen were slightly larger than in the $\langle 111\rangle$ specimen after oxidation under the same conditions, indicating a faster growth rate. At $1000^{\circ} \mathrm{C}$ the grain size was about 30 times larger for the $\langle 110\rangle$ specimen and about 4 times larger for the $\langle 111\rangle$ specimen than at $800^{\circ} \mathrm{C}$.

According to previous studies of oxide scale chemical composition by means of secondary neutral mass spectroscopy. (SNMS) [4], the concentration depth pro- 
TABLE

The results of AFM quantitative analyses of the oxide film formed on $\langle 110\rangle$ and $\langle 111\rangle$ specimens at 800 and $1000^{\circ} \mathrm{C}$.

\begin{tabular}{c|c|c|c|c}
\hline $\begin{array}{c}\text { Specimen } \\
\text { orientation }\end{array}$ & $\begin{array}{c}\text { Oxidation } \\
\text { temperature } \\
{\left[{ }^{\circ} \mathrm{C}\right]}\end{array}$ & $\begin{array}{c}\text { Exposure } \\
\text { time in air } \\
{[\mathrm{h}]}\end{array}$ & $\begin{array}{c}\text { Mean height } \\
\text { of oxide } \\
\text { crystallites } \\
{[\mathrm{nm}]}\end{array}$ & $\begin{array}{c}\text { Mean grain } \\
\text { size of oxide } \\
\text { crystallites } \\
{\left[\mu \mathrm{m}^{2}\right]}\end{array}$ \\
\hline$\langle 110\rangle$ & 800 & 0.5 & 6.6 & 0.008 \\
& 800 & 1.5 & 10.5 & 0.015 \\
& 1000 & 0.5 & 34.4 & 0.140 \\
$\langle 111\rangle$ & 1000 & 1.5 & 47.1 & 0.440 \\
\hline & 800 & 0.5 & 6.3 & 0.006 \\
& 1000 & 1.5 & 8.5 & 0.041 \\
& & 1.5 & 39.7 & 0.150
\end{tabular}

files showed no clear differences between the compositions of the scale formed on the $\langle 110\rangle$ and $\langle 111\rangle$ specimens. The distribution of ${ }^{16} \mathrm{O}$ and ${ }^{18} \mathrm{O}$ in the scales indicated that the alumina grows in both specimens by predominant outward diffusion of aluminium.

\section{Summary}

Atomic force microscopy was used for studying the oxidation products formed on the ODS alloy INCOLOY MA956 during oxidation up to $90 \mathrm{~min}$ in air at 800 and $1000^{\circ} \mathrm{C}$.

The AFM results demonstrated a crystalline character of the alumina scale that formed during the early stages of oxidation. The oxide scale morphology was slightly dependent on the crystallographic orientation of the bulk material, however SNMS investigations did not reveal significant differences in scale composition.

The study showed that AFM combined with other analytical methods can be a powerful technique for the quantitative microstructural investigation of oxide scales formed during the early stages of oxidation.

\section{References}

[1] A. Czyrska-Filemonowicz, D. Clemens, W.J. Quadakkers, Metall. Foundry Eng. 21, 319 (1995).

[2] B. Dubiel, W. Osuch, M. Wróbel, P.J. Ennis, A. Czyrska-Filemonowicz, J. Mater. Proc. Technol. 53, 121 (1995).

[3] A. Wasilkowska, B. Dubiel, A. Czyrska-Filemonowicz, Proc. XVII Conf. on Applied Crystallography, 31.08-4.09.97, Katowice-Wisła (Poland), to be published.

[4] A. Czyrska-Filemonowicz, K. Szot, A. Wasilkowska, A. Gil, W.J. Quadakkers, Solid State Ion., in press. 